\title{
How are OCD Patients and Family Members Dealing with the Waxing and Waning Pattern of the COVID-19 Pandemic? Results of a Longitudinal Observational Study
}

\author{
Hannelore LN Tandt ${ }^{1}$ (D) - Inge Debruyckere ${ }^{1} \cdot$ Lemke Leyman $^{1} \cdot$ Roos Colman $^{2}$. \\ Emiel A De Jaeghere ${ }^{3,4} \cdot$ Hanna Van Parys ${ }^{1} \cdot$ Chris Baeken $^{5,6} \cdot$ Christine Purdon $^{7}$. \\ Gilbert MD Lemmens ${ }^{1,5}$
}

Accepted: 30 May 2021 / Published online: 7 June 2021

(c) The Author(s), under exclusive licence to Springer Science+Business Media, LLC, part of Springer Nature 2021

\begin{abstract}
The current study aimed to investigate the impact of the COVID-19 pandemic on the mental health of people with OCD and the degree of family accommodation (FA) by live-in family members across phases of the lockdown measures imposed by the Belgian government. Forty-nine OCD patients and 26 live-in family members participated in the study. We assessed OCD symptom severity and FA of the live-in family members, as well as depressive symptoms, anxiety and stress levels and COVID-19 related psychological distress of patients and family members at four different timepoints: one month after the start of the lockdown $\left(T_{1}\right)$, during the gradual relaxation $\left(T_{2}\right)$, between the two waves $\left(T_{3}\right)$ and during the second wave $\left(\mathrm{T}_{4}\right)$. Results showed that although COVID-19 related stress increased and decreased in accordance with the waxing and waning pattern of the pandemic, OCD symptoms showed an initial slight increase followed by a decrease at $\mathrm{T}_{3}$ and again at $\mathrm{T}_{4}$. Changes in family members' accommodation of symptoms followed the same course as the OCD symptoms. Furthermore, OCD symptoms correlated with depressive symptoms, anxiety and stress levels and COVID-19 related distress at all timepoints. It is important to involve family members in the treatment of OCD even during a pandemic. Clinicians should also pay attention to symptoms of depression, anxiety and stress during OCD treatment. Further research is necessary to entangle the causal relationship between OCD symptoms, FA and symptoms of depression, anxiety and stress.
\end{abstract}

Keywords Obsessive-compulsive disorder · OCD · Family accommodation · COVID-19 • Pandemic

\section{Introduction}

The stress induced by the current COVID-19 pandemic has had a negative impact on the mental health of many patients with obsessive-compulsive disorder (OCD) [1]. Studies have found an increase in symptom severity $[2,3]$ as well as an increase in feelings of

Hannelore LN Tandt

Hannelore.tandt@uzgent.be

Extended author information available on the last page of the article 
loss of control, anxiety, hopelessness and depression [4]. This is likely attributable to the prevalence of disease reminders and hygienic recommendations [5, 6]. [4] also found that patients interpreted hygienic recommendations to be a "normalization and legitimization" of their OCD behaviors. Furthermore, OCD patients tend to respond to danger and uncertainty with more reassurance-seeking [7], [8]. The latter may affect the extent to which family members are accommodating their loved ones' OCD symptoms in the current pandemic. Family accommodation (FA), is evident in nearly $90 \%$ of family members, and refers to the adjustment that family members make to avoid or reduce their loved one's distress. Such adjustments range from performing the patient's compulsive rituals (e.g. checking and cleaning) for them to modifying daily routines (e.g. following the patient's rules or taking on tasks the person finds difficult because of the OCD).

Although these accommodations afford the patient temporary relief [9-11], FA is widely viewed as a factor in the persistence of OCD symptoms as it prevents the habituation of obsessions [12]. During the COVID-19 pandemic higher FA, especially reassuring and taking over, was reported by the family members since they worried more and felt more empathic towards their OCD relative [4]. However, although symptoms of OCD, anxiety, and depression and FA seemed to increase during the COVID-19 pandemic, it is less clear how they evolve over time and how they are associated with the course of the lockdown measures. It may be the case that an increase in COVID-19 threat results in an increase in family accommodation, because during lockdowns family members may be home together more and the costs of accommodating may be smaller (e.g., family members are not rushing to get to work) and there are potentially more COVID-19-related triggers for obsessions (contamination fears and fears of causing passive harm in particular). Moreover, lockdown is associated with greater symptoms of anxiety and depression, which in turn may exacerbate symptoms. However, during lockdown people do not venture out as much and may be more careful about hygiene, so the sense of personal threat presented by COVID-19 may be less. After a harsh lockdown in the middle of March 2020 in response to the rising number of cases, hospitalizations and deaths, a gradual relaxation occurred in the beginning of May 2020 allowing to travel again in July 2020. However, new restrictions on social contact, traveling and shopping were re-imposed in the beginning of October 2020 due to the second wave. This provides an opportunity to track symptoms and accommodation across phases of COVID-19 restrictions.

\section{Aims and Hypotheses of the Present Study}

The aims of the present study were twofold. First, given that previous studies, which have mainly focused on certain symptom dimensions or direct comparison between symptoms before and during the pandemic, we aimed to determine the effect of the waxing and waning pattern of the COVID-19 pandemic as represented by the total number of daily COVID-19 hospitalizations on OCD symptom severity of the patients. Second, we aimed to examine the effects of the patient's own depression, anxiety and stress levels and COVID-19 related distress and the family accommodation of the lived-in family members on the patient's OCD symptoms. It was hypothesized that: 1) patients would experience an increase in symptoms of OCD, depression, anxiety, stress, COVID-19 distress and FA as the number of COVID-19 hospitalizations increased; 2) OCD symptoms at each timepoint would be associated with participants' own levels of depression, anxiety, general and COVID-19 related stress and the level of family accommodation of live-in family members. 


\section{Methods}

\section{Recruitment and Selection}

Participants were recruited at the Centre for OCD of the Ghent University Hospital (UZ Gent) located in Belgium. All patients had previously been diagnosed with OCD by expert psychiatrists and clinical psychologists using the Structured Clinical Interview for the Diagnostic and Statistical Manual of Mental Disorders, Fourth or Fifth Edition (DSM-IV or DSM-5), as reported in their electronic medical records. Inclusion criteria were: (a) diagnosis of OCD, (b) age of patients between 18 and 65 years old, (c) speaking Dutch fluently. Exclusion criteria were: (a) current substance abuse and (b) psychotic symptoms. In addition, Dutch speaking family members, aged 18-65 years old, who were living in the same household as the patients with OCD were asked to participate in the study. This study was approved by the Ethical Committee of the Ghent University Hospital (UZ Gent, BC-07561).

\section{Demographics of Participants}

In total, 49 patients and 26 family members participated in the study. Demographic characteristics of the patients and family members are described in Table 1 . The mean age of the OCD patients was 34.7 yrs. (SD $=11.0$, range: $19-64$ ) with $69.4 \%$ being female and a mean symptom duration of 17.8 yrs. ( $\mathrm{SD}=10.4$, range: $1-47)$. Twenty-six, 16 male and 10 female ( 7 mothers, 16 male and 3 female partners) live-in family members participated as well. The mean age of the family members was 42.5 years ( $\mathrm{SD}=12.0$, range: $24-63)$. All patients and family members were Caucasian and living in the Flemish part of Belgium, except for one patient and partner who were living in the Netherlands.

\section{Procedure}

OCD symptoms of patients and family accommodation of the live-in family members were assessed via telephone or face-to-face interviews. These were conducted by the first and third author, a senior psychiatrist and a senior psychologist respectively, both working at the Centre for OCD of the Ghent University Hospital. 'Depressive symptoms, anxiety and stress levels' and 'COVID-19-related psychological distress' of patients and family members were assessed using REDCap, a secure, web-based platform for building and managing online surveys [13]. Between April 14th and May 15th, the baseline assessment $\left(\mathrm{T}_{1}\right)$ took place (for all but 3 participants (April 6th, May 18th and 22nd)), followed by three assessments $\left(\mathrm{T}_{2}-\mathrm{T}_{4}\right)$, respectively 1 month, 3 months and 6 months after the baseline assessment. The first assessment $\left(\mathrm{T}_{1}\right)$ took place one month after the start of the lockdown. The second assessment $\left(\mathrm{T}_{2}\right)$ fell during the gradual relaxation and the third $\left(\mathrm{T}_{3}\right)$ in the middle of the summer between the two waves. During the last assessment $\left(\mathrm{T}_{4}\right)$ new restrictions were re-imposed because of the second wave. The pattern of the lockdown measures followed the number of COVID hospitalizations. The total number of hospitalized COVID-19 patients in Belgium, with a population of approximately 11.5 million, was high during the first wave with 309 hospitalizations per million inhabitants at $\mathrm{T}_{1}(\mathrm{SD}=101.9$ range: 152-481) but with even higher hospitalization rates per million inhabitants per day 
Table 1 Description of Patients $(N=49)$ and Family Members $(N=26)$ Characteristics

\begin{tabular}{|c|c|c|c|}
\hline Variable & Group & $\begin{array}{l}\mathrm{N}(\%) \\
\text { Patient }\end{array}$ & $\begin{array}{l}\mathrm{N}(\%) \\
\text { Family member }\end{array}$ \\
\hline Gender & $\begin{array}{l}\text { Female } \\
\text { Male }\end{array}$ & $\begin{array}{l}34(69.4) \\
15(30.6)\end{array}$ & $\begin{array}{l}10(38.5) \\
16(61.5)\end{array}$ \\
\hline $\begin{array}{l}\text { Educational } \\
\text { attainment }\end{array}$ & $\begin{array}{l}\text { Primary school } \\
\text { Secondary school } \\
\text { Bachelor's degree } \\
\text { Master's degree }\end{array}$ & $\begin{array}{l}0(0) \\
23(46.9) \\
8(16.3) \\
18(36.7)\end{array}$ & $\begin{array}{l}1(3.8) \\
7(26.9) \\
8(30.8) \\
10(38.5)\end{array}$ \\
\hline $\begin{array}{l}\text { Employment } \\
\text { status }\end{array}$ & $\begin{array}{l}\text { Employed } \\
\text { Unemployed (health related) } \\
\text { Unemployed } \\
\text { Retired } \\
\text { Student } \\
\text { Other }\end{array}$ & $\begin{array}{l}19(38.8) \\
15(30.6) \\
4(8.2) \\
2(4.1) \\
7(14.3) \\
2(4.1)\end{array}$ & $\begin{array}{l}23(88.5) \\
1(3.8) \\
0(0) \\
1(3.8) \\
0(0) \\
1(3.8)\end{array}$ \\
\hline Marital status & $\begin{array}{l}\text { Single } \\
\text { Relationship not living together } \\
\text { Practically or common-law living together } \\
\text { Married } \\
\text { Widowed } \\
\text { Separated }\end{array}$ & $\begin{array}{l}16(32.7) \\
11(22.4) \\
4(8.2) \\
16(32.7) \\
0(0) \\
2(4.1)\end{array}$ & $\begin{array}{l}2(7.7) \\
8(30.8) \\
0(0) \\
15(57.7) \\
0(0) \\
1(3.8)\end{array}$ \\
\hline Living condition & $\begin{array}{l}\text { Living together } \\
\text { Living alone }\end{array}$ & $\begin{array}{l}42(85.7) \\
7(14.3)\end{array}$ & $\begin{array}{l}26(100) \\
0(0)\end{array}$ \\
\hline Children & $\begin{array}{l}\text { Children } \\
\text { No children }\end{array}$ & $\begin{array}{l}32(65.3) \\
17(34.7)\end{array}$ & $\begin{array}{l}5(19.2) \\
21(80.8)\end{array}$ \\
\hline Mental health treatment & $\begin{array}{l}\text { Current treatment provider } \\
\text { - GP } \\
\text { - Psychologist } \\
\text { - Psychiatrist } \\
\text { - Other } \\
\text { No current treatment }\end{array}$ & $\begin{array}{l}43(87.8) \\
8(18.6) \\
30(69.8) \\
40(93.0) \\
2(4.7) \\
6(12.2)\end{array}$ & \\
\hline Type of treatment (past or present) & $\begin{array}{l}\text { Medication } \\
\text { - SSRI } \\
\text { - SNRI } \\
\text { - Clomipramine } \\
\text { - Risperidone or aripiprazole } \\
\text { Psychotherapy } \\
\text { - CBT } \\
\text { - System therapy } \\
\text { - Psychodynamic therapy } \\
\text { Neuromodulation (TMS, DBS, ECT) }\end{array}$ & $\begin{array}{l}45(91.8) \\
36(80.0) \\
16(35.5) \\
15(33.3) \\
10(22.2) \\
44(89.8) \\
41(93.2) \\
3(6.8) \\
3(6.8) \\
16(32.7)\end{array}$ & \\
\hline $\begin{array}{l}\text { Positive family history of psychiatric } \\
\text { disorders }\end{array}$ & $\begin{array}{l}\text { OCD } \\
\text { Depressive disorder } \\
\text { Anxiety disorder } \\
\text { Substance use disorder } \\
\text { Psychotic disorder } \\
\text { Tic disorder } \\
\text { Autism } \\
\text { ADHD } \\
\text { Other } \\
\text { None }\end{array}$ & $\begin{array}{l}12(24.5) \\
25(51.0) \\
14(28.6) \\
19(38.8) \\
2(4.1) \\
1(2.0) \\
3(6.1) \\
5(10.2) \\
4(8.2) \\
11(22.4)\end{array}$ & \\
\hline
\end{tabular}


during the second wave at $\mathrm{T}_{4} 468(\mathrm{SD}=169.4$ range: $155-649) . \mathrm{T}_{2}$ and $\mathrm{T}_{3}$ felt between the two waves with lower hospitalization rates per million inhabitants: 85 ( $\mathrm{SD}=39.7$ range: $34-162)$ at $\mathrm{T}_{2}$ and $21(\mathrm{SD}=5.0$ range: $13-27)$ at $\mathrm{T}_{3}$ Fig. 1.

'OCD symptom severity' was assessed using the validated Dutch version of the YaleBrown Obsessive-Compulsive Scale (Y-BOCS) [14-16]. This is a clinician-rated 10-item scale, consisting of two subscales of obsessions (5 items) and compulsions (5 items) to determine OCD severity, resulting in a total score from 0 to 40 . In the current study, Cronbach's alphas of the total Y-BOCS and the subscales of obsessions and compulsions were $0.96,0.93$ and 0.93 respectively at $\mathrm{T}_{1}$.

'Family accommodation' was measured using the Dutch version of the interviewerrated Family Accommodation Scale for Obsessive-Compulsive Disorder (FAS-IR) [17]. The 12-item clinician-rated questionnaire assesses the types of accommodation
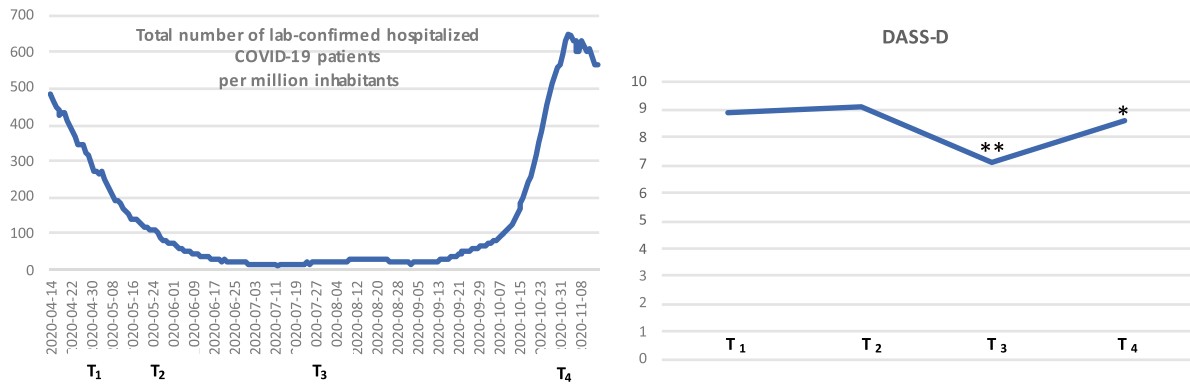

Y-BOCS

DASS-A
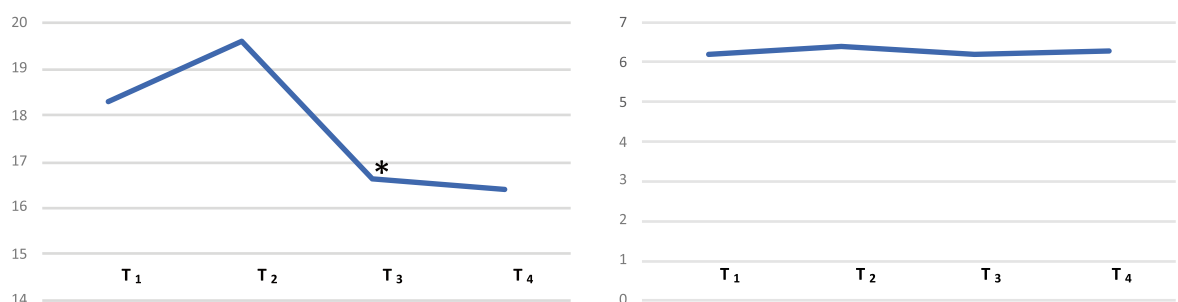

CPDI

DASS-S
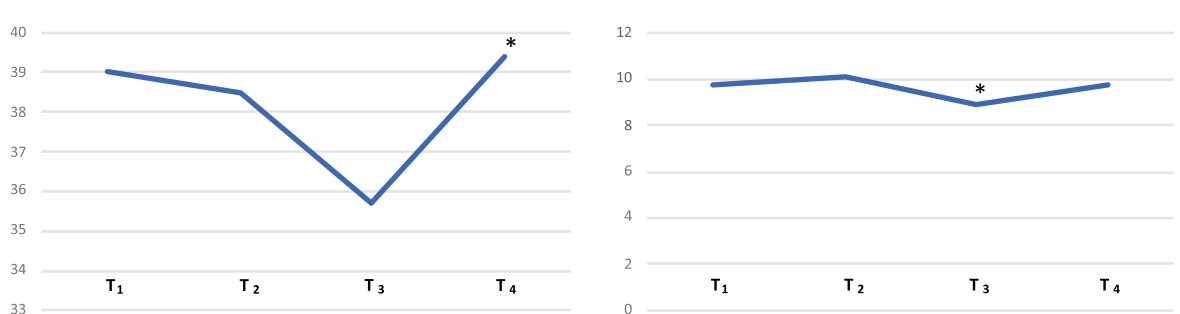

Fig. 1 Total number of lab-confirmed hospitalized COVID-19 patients in Belgium (data from www.scien sano.be) and mean scores for Y-BOCS, CPDI, depression (DASS-D), anxiety (DASS-A) and stress (DASS$\mathrm{S})$ of the patients $(N=49)$ at the different timepoints $\left(\mathrm{T}_{1}, \mathrm{~T}_{2}, \mathrm{~T}_{3}, \mathrm{~T}_{4}\right)$ 
behaviours family members engage in and their associated interference. The total score of these items (0-48) indicates the level of family accommodation since each answer varies from 0 to 4 . In this study the Cronbach's alpha was 0.90 at $\mathrm{T}_{1}$.

'Depressive symptoms, anxiety and stress levels' were investigated with the Dutch version of the self-reported 21-item Depression, Anxiety and Stress Scale (DASS-21) $[18,19]$. It consists of 21 items, each rated on a four-point scale from 0 (hardly ever) to 3 (almost always). The Cronbach's alphas for depression, anxiety and stress were 0.93 , $0.89,0.93$ respectively at $\mathrm{T}_{1}$.

'Specific distress regarding Covid-19' was measured by the Dutch translation of the Covid-19 Peritraumatic Distress Index (CPDI). This self-reported questionnaire inquiries about the frequency of anxiety, depression, specific phobias, cognitive change, avoidance and compulsive behavior, physical symptoms and loss of social functioning in the past week. The scores range from 0 to 100 , with higher scores indicating more distress [20]. In the current study the Cronbach's alpha of the CPDI was 0.94 at $\mathrm{T}_{1}$.

'The waxing and waning pattern of the COVID-19 pandemic in Belgium' was represented by the evolution of the total number of daily hospitalized patients with COVID19 in Belgium (www.sciensano.be) as the daily newly confirmed COVID-19 cases were initially not a very good indicator of the pandemic's progress because of a restricted testing policy and capacity.

\section{Analysis}

All statistical tests were performed at the two-sided 5\% significance level, unless otherwise specified and were performed using Statistical Package of the Social Sciences (SPSS, version 26). To describe OCD, stress, anxiety and depressive symptoms of the patients over time, mixed models were applied for each outcome measure (Y-BOCS and FAS, DASS-21 and CPDI) separately, with patients defined as subjects and a compound symmetry (CS) variance covariance structure. All available data were included in the analyses, as the mixed model approach is known to handle missing data in longitudinal studies appropriately under the MAR or MCAR assumption [21].

To compare COVID stress and depressive, anxiety and stress scores between family members and patients Pearson correlations and linear regression were applied for each time point separately. The analyses were performed on all the available pairs for that specific time point. To assess the reliability of the used scales, the Cronbach's alpha was calculated for each scale at $\mathrm{T}_{1}$. No correction for multiple testing was applied.

\section{Results}

The overall response rate was high during all timepoints, non-participation occurred for Y-BOCS at $\mathrm{T}_{1}$ and $\mathrm{T}_{3}$ (one patient) and $\mathrm{T}_{4}$ (two patients) and for CPDI and DASS-21 (using REDCAP) at $\mathrm{T}_{3}$ and $\mathrm{T}_{4}$ (one patient). A common reason for non-participation included more arousal and fear due to re-evaluation and attention directed to the complaints. We did not miss any assessments at any timepoint among family members. 


\section{OCD, Stress, Anxiety and Depressive Symptoms of the Patients Over Time}

In the total patient sample $(N=49)$, the pattern of the lockdown measures and the COVID19 hospitalization rates were reflected in symptom severity, with the lowest scores on OCD, stress, anxiety and depressive measures at $\mathrm{T}_{3}$. OCD symptoms further decreased at $\mathrm{T}_{4}$ whereas stress, anxiety and depressive scores worsened again at $\mathrm{T}_{4}$. OCD symptoms significantly improved from $\mathrm{T}_{2}$ to $\mathrm{T}_{3}(\mathrm{p}<.05)$ and $\mathrm{T}_{2}$ to $\mathrm{T}_{4}(\mathrm{p}<.01)$. COVID-19 stress significantly decreased from $\mathrm{T}_{1}$ to $\mathrm{T}_{3}(\mathrm{p}<.05)$ and increased again from $\mathrm{T}_{3}$ to $\mathrm{T}_{4}(\mathrm{p}<.05)$. Depressive symptoms significantly improved from $\mathrm{T}_{1}$ to $\mathrm{T}_{3}(\mathrm{p}<.01)$ and from $\mathrm{T}_{2}$ to $\mathrm{T}_{3}(\mathrm{p}<.01)$ but worsened again from $\mathrm{T}_{3}$ to $\mathrm{T}_{4}(\mathrm{p}<.05)$. Stress improved significantly from $\mathrm{T}_{2}$ to $\mathrm{T}_{3}(\mathrm{p}<.05)$. However, no significant changes were found for anxiety over time. Table 2.

Significant differences $(\mathrm{p}<.01)$ were found on stress, anxiety, depressive and COVID-19 distress scores at the different time points between family members $(N=26)$ and patients $(N=26)$. Scores of the family members were in the normal range at all timepoints whereas patient's scores were moderately severe (see Table 3. No significant differences in age, gender, Y-BOCS, CPDI, DASS-D, DASS-A and DASS-S scores were found at baseline $\left(\mathrm{T}_{1}\right)$ between the total patient group $(N=49)$ and the patient group whose live-in family members were interviewed $(N=26)$.

These results confirmed partly the first hypothesis. Depressive symptoms, stress levels and COVID-19 related stress increased and decreased in accordance with the waxing and waning pattern of the pandemic, but OCD symptoms showed an initial slight increase followed by a decrease at $\mathrm{T}_{3}$ and again at $\mathrm{T}_{4}$.

\section{Correlations of OCD Symptoms of the Patients with the Own Depression, Anxiety and (COVID-19) Stress and FA of Family Members During the Pandemic}

Patients' Y-BOCS scores were significantly associated with their own CPDI, DASS-D, DASS-A scores at the different timepoints $(\mathrm{p}<.01)$ and DASS-S scores at $\mathrm{T}_{1}, \mathrm{~T}_{2}$ and $\mathrm{T}_{4}$ $(\mathrm{p}<.01)$ and at $\mathrm{T}_{3}(\mathrm{p}<.05)$ Table 4 . In addition, Y-BOCS scores were significantly associated with FAS scores, an increase in Y-BOCS score of 10 points was associated with an increase of 3 points on FAS scores (95\% CI: 0.11 to 0.48$)(\mathrm{p}<.01)$.

Table 2 Mean scores (standard deviation) of Y-BOCS, CPDI, depression (DASS-D), anxiety (DASS-A) and stress (DASS-S) of the patients $(N=49)$ at the different time points

\begin{tabular}{llrll}
\hline & $\mathrm{T}_{1}$ & \multicolumn{1}{l}{$\mathrm{T}_{2}$} & \multicolumn{1}{l}{$\mathrm{T}_{3}$} & \multicolumn{1}{l}{$\mathrm{T}_{4}$} \\
& $\mathrm{M}(\mathrm{SD})$ & $\mathrm{M}(\mathrm{SD})$ & $\mathrm{M}(\mathrm{SD})$ & $\mathrm{M}(\mathrm{SD})$ \\
\hline Patients $n=49$ & & & & \\
Y-BOCS & $18.3(1.23)$ & $19.6(1.24)$ & $16.6(1.24)^{\mathrm{a}}$ & $16.4(1.25)^{\mathrm{b}}$ \\
CPDI & $39.0(2.44)$ & $38.5(2.44)$ & $35.7(2.45)^{\mathrm{c}}$ & $39.4(2.45)^{\mathrm{d}}$ \\
DASS-D & $8.9(0.80)$ & $9.1(0.80)$ & $7.1(0.81)^{\mathrm{e}}$ & $8.6(0.81)^{\mathrm{f}}$ \\
DASS-A & $6.2(0.67)$ & $6.4(0.67)$ & $6.2(0.67)$ & $6.3(0.67)$ \\
DASS-S & $9.7(0.75)$ & $10.1(0.75)$ & $8.9(0.75)^{\mathrm{g}}$ & $9.8(0.75)$ \\
\hline
\end{tabular}

\footnotetext{
${ }^{\mathrm{a}}$ significant decrease from $\mathrm{T}_{2}$ to $\mathrm{T}_{3}(\mathrm{p}<.05)$

${ }^{\mathrm{b}}$ significant decrease from $\mathrm{T} 2$ to $\mathrm{T}_{4}(\mathrm{p}<.01)$

${ }^{\mathrm{c}}$ significant decrease from $\mathrm{T}_{1}$ to $\mathrm{T}_{3}(\mathrm{p}<.05)$

${ }^{d}$ significant increase from $\mathrm{T}_{3}$ to $\mathrm{T}_{4}(\mathrm{p}<.05)$

${ }^{\mathrm{e}}$ significant decrease from $\mathrm{T}_{1}$ to $\mathrm{T}_{3}$ and $\mathrm{T}_{2}$ to $\mathrm{T}_{3}(\mathrm{p}<.01)$

${ }^{\mathrm{f}}$ significant increase from $\mathrm{T}_{3}$ to $\mathrm{T}_{4}(\mathrm{p}<.05)$, ${ }^{\mathrm{g}}$ significant decrease from $\mathrm{T}_{2}$ to $\mathrm{T}_{3}(\mathrm{p}<.05)$
} 


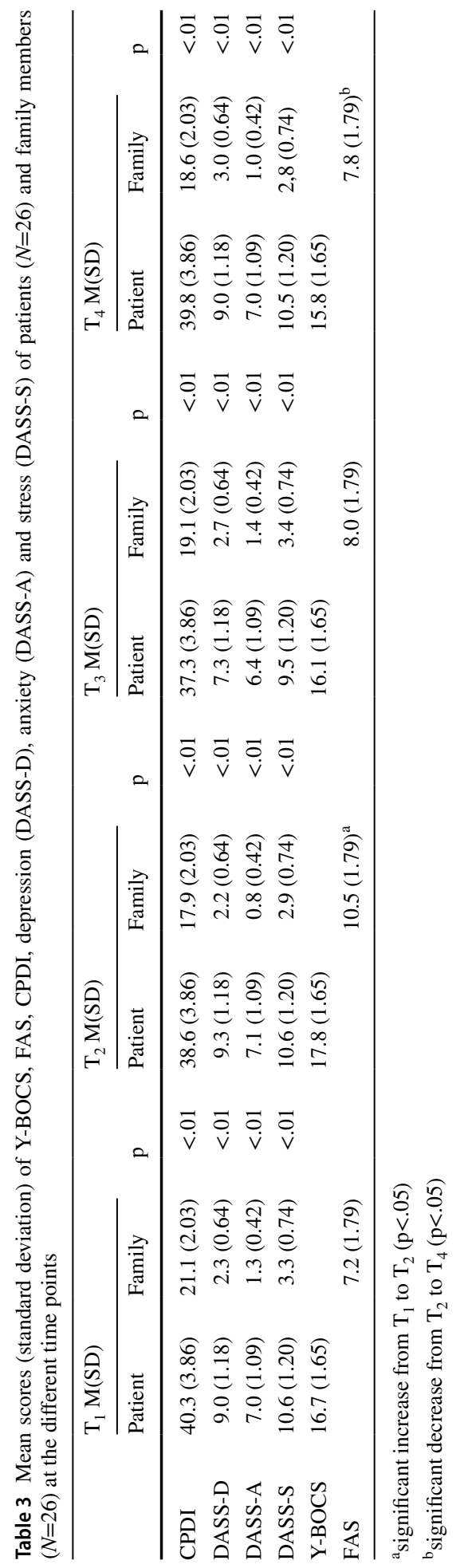


Further, we found a significant association of FAS scores with patients' CPDI scores at $\mathrm{T}_{4}(\mathrm{p}<.01)$, with the DASS-D and DASS-A at $\mathrm{T}_{4}(\mathrm{p}<.05)$ and with the DASS-S at $\mathrm{T}_{1}, \mathrm{~T}_{2}$ and $\mathrm{T}_{4}(\mathrm{p}<.05)$. There were no significant relationships between FAS and family members' CPDI, DASS-D, DASS-A and DASS-S scores Table 4. FAS scores significantly increased from $\mathrm{T}_{1}$ to $\mathrm{T}_{2}(\mathrm{p}<.05)$ and decreased from $\mathrm{T}_{2}$ to $\mathrm{T}_{4}(\mathrm{p}<.05)$ in family members Table 3 , following the same time course of patients' Y-BOCS.

These results confirmed the second hypothesis as OCD symptoms correlated with depressive symptoms, anxiety and stress levels and COVID-19 related distress at all timepoints and OCD symptoms are strongly associated with family accommodation.

\section{Discussion}

The current study aimed to evaluate changes in OCD symptom severity and their associations with the own mental health and family accommodation of live-in family members during the phases of the COVID-19 pandemic from March until October of 2020. It was hypothesized that patients would experience an increase in symptoms of OCD, depression, anxiety, stress, COVID-19 distress and FA as the number of COVID-19 hospitalizations increased. Furthermore, we assumed that OCD symptoms at each timepoint would be associated with participants' own levels of depression, anxiety, general and COVID-19 related stress and the level of family accommodation of live-in family members.

Although patients' OCD symptoms increased slightly from the beginning of the pandemic until the first lockdown, they improved as the pandemic progressed. This is in contrast with previous studies highlighting the negative impact of the COVID-19 pandemic on OCD symptoms [22, 23], independent of different symptom dimensions [2, 3]. It may be that there was an initial sensitization that exacerbated symptoms, followed by habituation to the stimuli evoking them. It may also be the case that as the pandemic continued people were able to develop better insight into their obsessions and view them as less threatening, etc. [24]. It is also likely that at least some patients continued to isolate even during the gradual relaxation of the lockdown measures, allowing them to avoid the range of OCD triggers they would normally encounter. Finally, some people with OCD may have felt vindicated or safer now that people were following much more stringent hygiene protocols than at pre-pandemic, even when lockdown restrictions relaxed.

It is also important to note that the accessibility and nature of treatment changed across these timeframes. During the first wave and initial lockdown treatment availability was greatly curtailed [4]. However, during the summer months and the second wave treatment availability increased as therapists moved to online platforms and appropriate safety protocols were established for in-person treatment. Indeed, there is evidence that people with OCD who were in treatment have coped well during the pandemic [25, 26]. However, although OCD symptoms decreased, COVID-19 distress and depression worsened again during the second wave. This may be due to job loss, uncertainty, isolation, and other factors that can exacerbate depressive symptoms [4, 27]. The increase of the COVID-19 related stress may partly be explained by the rise of COVID-19 cases and hospitalizations.

During the pandemic, patients' stress, anxiety and depressive symptoms consistently remained higher than those of family members Table 3. This may reflect the ten times higher prevalence of major depressive disorders in OCD patients compared to the general population [28]. Similarly, a high comorbidity with different anxiety disorders, ranging from $27-37 \%$ has also been reported [29]. No information about comorbidity 


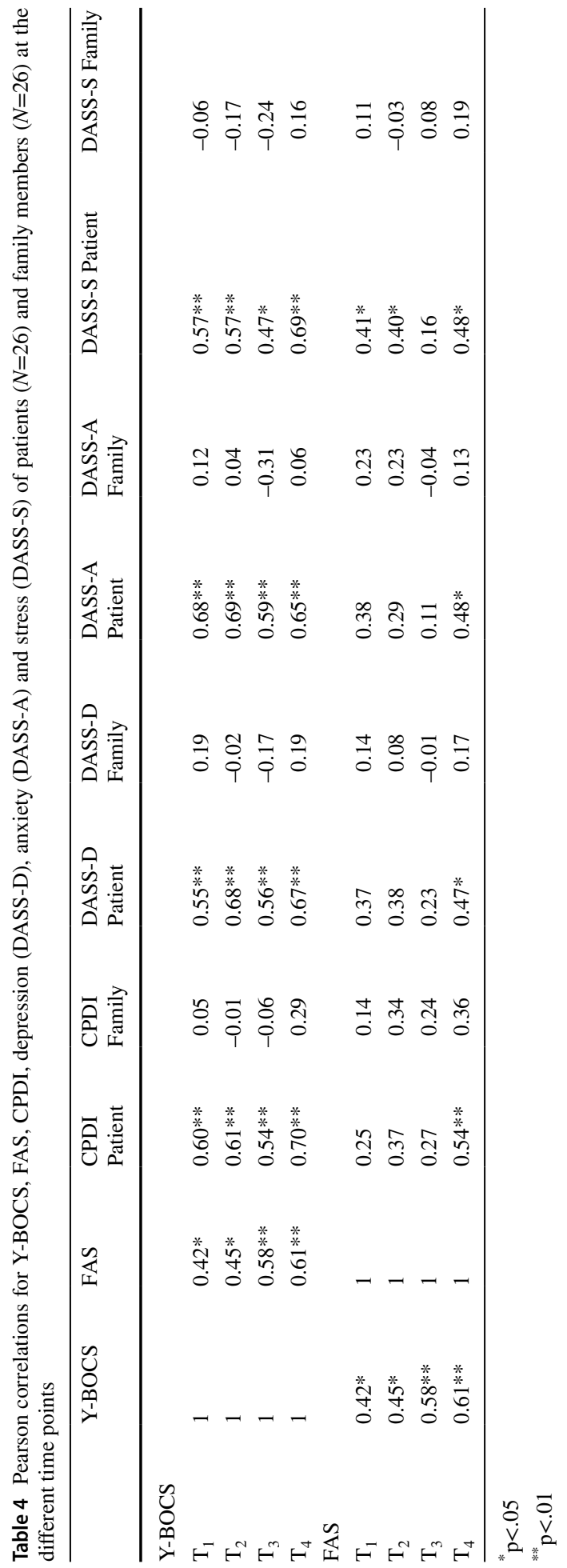


in our sample was available. Further, people with pre-existing mental disorders, and especially with OCD, are more prone to relapses and stress during pandemics $[1,30]$. Finally, even though feelings of loss of control increase fear and uncertainty in all people as the trajectory of the pandemic is constantly changing [31], this may be even worse in OCD patients as beliefs of losing control can worsen their mental health [32].

As expected, an association was found between the OCD symptoms severity and the symptoms of depression, anxiety and stress levels and COVID-19 related distress of patients at all timepoints. This result is in accordance with several studies showing that a previous diagnosis of a mental disorder is significantly associated with depression and anxiety [33] and stress [34] and COVID-19 related distress [2, 3, 8] is associated with OCD symptoms. However, in Pan et al. [1] people with severe or chronic mental disorders the COVID-19 pandemic did not seem to exhibit an exacerbation of their pre-existing high levels of symptoms. According to Pan's study this could be due to having a structured and fixed daily routine that serves as a resilience factor, or by simply natural remission.

The degree of family accommodation was positively correlated with the OCD symptom severity at all timepoints. This is in line with the results of a recent study where patients who experienced a global worsening of their OCD reported an increased FA [22]. It is well known that family members are more prone to accommodate in case of severe OCD symptoms and that FA may contribute to OCD symptom severity by facilitating compulsions [35-38]. Moreover, FA was also correlated with symptoms of depression, anxiety levels and COVID-19 related distress of patients at $\mathrm{T}_{4}$ and with stress levels of patients at $\mathrm{T}_{1}, \mathrm{~T}_{2}$ and $\mathrm{T}_{4}$. It is difficult to explain why anxiety and depressive symptoms of the patients and not of the family members were associated with FA as a positive correlation was expected in family members and not in patients $[36,39]$. Further research is needed to clarify this, but it could be that family members have a low tolerance for seeing their loved ones in distress and so seek to intervene quickly to soothe it, as Calvocoressi et al. [17] found that most family members accommodate in an effort to diminish the patient's distress. The question whether higher levels of FA are resulting from or causing more severe OCD symptoms and/or more anxiety, depression and stress in patients warrants further investigation. For the time being, our results point to the importance of involving family members in the treatment of OCD even during this pandemic since high levels of FA may lead to a less favorable treatment response of patients [10].

\section{Limitations}

Several factors limit the generalizability of our results: the small sample size, the difference in number of included patients and family members, and the lack of followup assessments after 6 months. The participants were all recruited from one specialist OCD clinic, and therefore generalizability of findings to other geographic regions which had different patterns of COVID-19 outbreaks may be limited. Further, since the severity of pre-existing levels of OCD symptoms and comorbidity and the amount of received therapy may strongly vary between the participants, these factors could have influenced our results. 


\section{Conclusions}

In conclusion, the results of the present study indicate that OCD symptoms may actually improve during a pandemic, contrary to what might be expected. However, symptoms remain strongly associated with family accommodation. Therefore, it is important to involve family members in the treatment of OCD even during a pandemic. Clinicians should also pay attention to symptoms of depression, anxiety and stress during OCD treatment. Further research is necessary to entangle the causal relationship between OCD symptoms, FA and symptoms of depression, anxiety and stress.

Abbreviations OCD: Obsessive-Compulsive Disorder; COVID-19: Coronavirus Disease-2019; FA: Family Accommodation; DSM-IV: Diagnostic and Statistical Manual of Mental Disorders, Fourth Edition; DSM5: Diagnostic and Statistical Manual of Mental Disorders, Fifth Edition; REDCap: Research Electronic Data Capture; Y-BOCS: Yale-Brown Obsessive-Compulsive Scale; FAS-IR: interviewer-rated Family Accommodation Scale for Obsessive-Compulsive Disorder; DASS-21: Depression, Anxiety and Stress Scale; CPDI: Covid-19 Peritraumatic Distress Index; SPSS: Statistical Package of the Social Sciences; CS: Compound Symmetry; MAR: Missing At Random; MCAR: Missing Completely At Random

Acknowledgements The authors would like to thank the patients and family members who participated in this research. EDJ is an 'Aspirant' (Ph.D. Fellow) of the Research Foundation-Flanders (FWO) (Grant Number: 1195919 N).

Funding This research was not supported by any specific grant from funding agencies in the public, commercial, or not-for-profit sectors.

Data Availability Statement HT and RC had full access to all of the data in the study and take responsibility for the accuracy of the data analysis and the integrity of the data.

\section{Declarations}

Ethics Approval This study was approved by the Ethical Committee of Ghent University Hospital (UZ Gent, BC-07561).

Consent to Participate Informed consent was obtained from all individual participants included in the study.

Consent for Publication Informed consent was obtained from all individual participants included in the study.

Conflict of Interest EDJ reports non-financial support from Pfizer and non-financial support from PharmaMar, all outside the submitted work and institutional (not personal). All other authors declare that they have no conflicts of interest.

\section{References}

1. Pan KY, Kok AAL, Eikelenboom M, Horsfall M, Jörg F, Luteijn RA, Penninx BWJH. The mental health impact of the COVID-19 pandemic on people with and without depressive, anxiety, or obsessive-compulsive disorders: a longitudinal study of three Dutch case-control cohorts. The Lancet Psychiatry. 2021. https://doi.org/10.1016/S2215-0366(20)30491-0.

2. Khosravani V, Aardema F, Ardestani SMS, Sharifi Bastan F. The impact of the coronavirus pandemic on specific symptom dimensions and severity in OCD: A comparison before and during COVID-19 in the context of stress responses. J Obsessive Compuls Relat Disord. 2021. https://doi. org/10.1016/j.jocrd.2021.100626.

3. Khosravani V, Asmundson GJG, Taylor S, Sharifi Bastan F, Samimi Ardestani SM. The Persian COVID stress scales (Persian-CSS) and COVID-19-related stress reactions in patients with obsessive-compulsive and anxiety disorders. J Obsessive Compuls Relat Disord. 2021. https://doi.org/10. 1016/j.jocrd.2020.100615. 
4. Tandt HLN, Van Parys H, Leyman L, Purdon C, Lemmens GMD. How are OCD patients and their families coping with the COVID-19 pandemic ? A qualitative study. Curr Psychol. 2021. https://doi. org/10.1007/s12144-021-01724-5.

5. Fineberg NA, Van Ameringen M, Drummond L, Hollander E, Stein DJ, Geller D, Dell'Osso B. How to manage obsessive-compulsive disorder (OCD) under COVID-19: A clinician's guide from the International College of Obsessive Compulsive Spectrum Disorders (ICOCS) and the Obsessive-Compulsive and Related Disorders Research Network (OCRN) of the Europ. Compr Psychiatry. 2020. https://doi. org/10.1016/j.comppsych.2020.152174.

6. Fontenelle LF, Miguel EC. The impact of coronavirus (COVID-19) in the diagnosis and treatment of obsessive-compulsive disorder. Depress Anxiety. 2020. https://doi.org/10.1002/da.23037.

7. Shafran R, Coughtrey A, Whittal M. Recognising and addressing the impact of COVID-19 on obsessive-compulsive disorder. The Lancet Psychiatry. 2020. https://doi.org/10.1016/S2215-0366(20) 30222-4.

8. Wheaton MG, Messner GR, Marks JB. Intolerance of uncertainty as a factor linking obsessive-compulsive symptoms, health anxiety and concerns about the spread of the novel coronavirus (COVID-19) in the United States. J Obsessive Compuls Relat Disord. 2021. https://doi.org/10.1016/j.jocrd.2020.100605.

9. Calvocoressi L, Lewis B, Harris M, Trufan SJ, Goodman WK, McDougle CJ, Price LH. Family accommodation in obsessive-compulsive disorder. Am J Psychiatry. 1995. https://doi.org/10.1176/ajp. 152.3.441.

10. Renshaw KD, Steketee G, Chambless DL. Involving family members in the treatment of OCD. Cogn Behav Ther. 2005. https://doi.org/10.1080/16506070510043732.

11. Shimshoni Y, Shrinivasa B, Cherian A, Lebowitz E. Family accommodation in psychopathology: A synthesized review. Indian J Psychiatry. 2019. https://doi.org/10.4103/psychiatry.indianjpsychiatry_ 530_18.

12. Albert U, Baffa A, Maina G. Family accommodation in adult obsessive-compulsive disorder: Clinical perspectives. Psychol Res Behav Manag. 2017. https://doi.org/10.2147/PRBM.S124359.

13. Harris PA, Taylor R, Thielke R, Payne J, Gonzalez N, Conde JG. A metadata-driven methodology and workflow process for providing translational research informatics support. J Biomed Inform. 2009.

14. Arrindell WA, De Vlaming IH, Eisenhardt BM, Van Berkum DE, Kwee MGT. Cross-cultural validity of the yale-brown obsessive compulsive scale. J Behav Ther Exp Psychiatry. 2002. https://doi.org/10. 1016/S0005-7916(02)00047-2.

15. Goodman WK, Price LH, Rasmussen SA, Mazure C, Delgado P, Heninger GR, Charney DS. The Yale-Brown Obsessive Compulsive Scale: II. Validity. Arch Gen Psychiatry. 1989. https://doi.org/10. 1001/archpsyc.1989.01810110054008.

16. Goodman WK, Price LH, Rasmussen SA, Mazure C, Fleischmann RL, Hill CL, Charney DS. The YaleBrown Obsessive Compulsive Scale: I. Development, Use, and Reliability. Arch Gen Psychiatry. 1989. https://doi.org/10.1001/archpsyc.1989.01810110048007.

17. Calvocoressi L, Mazure CM, Kasl SV, Skolnick J, Fisk D, Vegso SJ, Price LH. Family accommodation of obsessive-compulsive symptoms: Instrument development and assessment of family behavior. J Nerv Ment Dis. 1999. https://doi.org/10.1097/00005053-199910000-00008.

18. de Beurs E, Van Dyck R, Marquenie LA, Lange A, Blonk RWB. De DASS: Een vragenlijst voor het meten van depressie, angst en stress [The DASS: A questionnaire for the measurement of depression, anxiety, and stress]. Gedragstherapie. 2020.

19. Lovibond PF, Lovibond SH. The structure of negative emotional states: Comparison of the Depression Anxiety Stress Scales (DASS) with the Beck Depression and Anxiety Inventories. Behav Res Ther. 1995. https://doi.org/10.1016/0005-7967(94)00075-U.

20. Qiu J, Shen B, Zhao M, Wang Z, Xie B, Xu Y. A nationwide survey of psychological distress among Chinese people in the COVID-19 epidemic: Implications and policy recommendations. Gen Psychiatry. 2020. https://doi.org/10.1136/gpsych-2020-100213.

21. Ibrahim JG, Molenberghs G. Missing data methods in longitudinal studies: A review. Test. 2009. https://doi.org/10.1007/s11749-009-0138-x.

22. Benatti B, Albert U, Maina G, Fiorillo A, Celebre L, Girone N, Dell'Osso B. What happened to patients with obsessive compulsive disorder during the COVID-19 pandemic? a multicentre report from tertiary clinics in Northern Italy. Front Psychiatry. 2020.https://doi.org/10.3389/fpsyt.2020. 00720.

23. Tanir Y, Karayagmurlu A, Kaya İ, Kaynar TB, Türkmen G, Dambasan BN, Coşkun M. Exacerbation of obsessive compulsive disorder symptoms in children and adolescents during COVID-19 pandemic. Psychiatry Res. 2020. https://doi.org/10.1016/j.psychres.2020.113363. 
24. Jelinek L, Moritz S, Miegel F, Voderholzer U. Obsessive-compulsive disorder during COVID-19: Turning a problem into an opportunity? J Anxiety Disord. 2021. https://doi.org/10.1016/j.janxdis. 2020.102329 .

25. Kuckertz JM, Van Kirk N, Alperovitz D, Nota JA, Falkenstein MJ, Schreck M, Krompinger JW. Ahead of the Curve: Responses From Patients in Treatment for Obsessive-Compulsive Disorder to Coronavirus Disease 2019. Front Psychol. 2020. https://doi.org/10.3389/fpsyg.2020.572153.

26. Schwartz-Lifshitz M, Basel D, Lang C, Hertz-Palmor N, Dekel I, Zohar J, Gothelf D. Obsessive compulsive symptoms severity among children and adolescents during COVID-19 first wave in Israel. J Obsessive Compuls Relat Disord. 2021. https://doi.org/10.1016/j.jocrd.2020.100610.

27. Fancourt D, Steptoe A, Bu F. Trajectories of anxiety and depressive symptoms during enforced isolation due to COVID-19 in England: a longitudinal observational study. The Lancet Psychiatry. 2021. https://doi.org/10.1016/S2215-0366(20)30482-X.

28. Denys D, Tenney N, Van Megen HJGM, De Geus F, Westenberg HGM. Axis I and II comorbidity in a large sample of patients with obsessive-compulsive disorder. J Affect Disord. 2004. https://doi.org/10. 1016/S0165-0327(03)00056-9.

29. Pinto A, Mancebo MC, Eisen JL, Pagano ME, Rasmussen SA. The Brown Longitudinal Obsessive Compulsive Study: Clinical features and symptoms of the sample at intake. J Clin Psychiatry. 2006;67(5):703-11. https://doi.org/10.4088/JCP.v67n0503.

30. Duan L, Zhu G. Psychological interventions for people affected by the COVID-19 epidemic. The Lancet Psychiatry. 2020. https://doi.org/10.1016/S2215-0366(20)30073-0.

31. Han PKJ, Zikmund-Fisher BJ, Duarte CW, Knaus M, Black A, Scherer AM, Fagerlin A. Communication of Scientific Uncertainty about a Novel Pandemic Health Threat: Ambiguity Aversion and Its Mechanisms. J Health Commun. 2018. https://doi.org/10.1080/10810730.2018.1461961.

32. McLaren S, Crowe SF. The contribution of perceived control of stressful life events and thought suppression to the symptoms of obsessive-compulsive disorder in both non-clinical and clinical samples. $\mathbf{J}$ Anxiety Disord. 2003. https://doi.org/10.1016/S0887-6185(02)00224-4.

33. González-Sanguino C, Ausín B, Castellanos MÁ, Saiz J, López-Gómez A, Ugidos C, Muñoz M. Mental health consequences during the initial stage of the 2020 Coronavirus pandemic (COVID-19) in Spain. Brain Behav Immun. 2020. https://doi.org/10.1016/j.bbi.2020.05.040.

34. Adams TG, Kelmendi B, Brake CA, Gruner P, Badour CL, Pittenger C. The role of stress in the pathogenesis and maintenance of obsessive-compulsive disorder. Chronic Stress. 2018. https://doi.org/10.1177/ 2470547018758043.

35. Albert U, Bogetto F, Maina G, Saracco P, Brunatto C, Mataix-Cols D. Family accommodation in obsessive-compulsive disorder: Relation to symptom dimensions, clinical and family characteristics. Psychiatry Res. 2010. https://doi.org/10.1016/j.psychres.2009.06.008.

36. Gomes JB, Van Noppen B, Pato M, Braga DT, Meyer E, Bortoncello CF, Cordioli AV. Patient and family factors associated with family accommodation in obsessive-compulsive disorder. Psychiatry Clin Neurosci. 2014. https://doi.org/10.1111/pcn.12172.

37. Lebowitz ER, Panza KE, Su J, Bloch MH. Family accommodation in obsessive-compulsive disorder. Expert Rev Neurother. 2012. https://doi.org/10.1586/ern.11.200.

38. Van Noppen B, Steketee G. Testing a conceptual model of patient and family predictors of obsessive compulsive disorder (OCD) symptoms. Behav Res Ther. 2009. https://doi.org/10.1016/j.brat.2008.10. 005.

39. Amir N, Freshman M, Foa EB. Family distress and involvement in relatives of obsessive-compulsive disorder patients. J Anxiety Disord. 2000. https://doi.org/10.1016/S0887-6185(99)00032-8.

Publisher's Note Springer Nature remains neutral with regard to jurisdictional claims in published maps and institutional affiliations.

Hannelore LN Tandt is Psychiatrist and Cognitive Behavioural Therapist at the Ghent University Hospital and head of the Centre of OCD. Her research focuses on family accommodation, psychotherapy and neuromodulation in obsessive-compulsive disorders.

Inge Debruyckere is a $5^{\text {th }}$ year resident Psychiatrist at the Ghent University Hospital and is training to become a Cognitive Behavioural Therapist. 
Lemke Leyman is Psychologist and Cognitive Behavioural Therapistat the Ghent University Hospital. She is an expert in conducting psychotherapy in the field of obsessive-compulsive disorders and her research also focuses on this topic.

Roos Colman is Biostatistician at the Biostatistics Unit, Department of Public Health and Primary Care andprovides statistical consultancy to researchers affiliated to the Faculty of Medicine and Health Sciences.

Emiel A De Jaeghere is InternalMedicine Resident and Ph.D. Fellow at Ghent University Hospital. His researchfocuses on the treatment of tumors of the female genital tract andimmuno-oncology.

Hanna Van Parys is psychologist and couple and family therapist at the Ghent University Hospital. She is an expert in qualitative research methods and supervises research in the field of couple- and family studies.

Chris Baeken is Associate Professor in Psychiatry, Department Head and Skin, Ghent University and Head of the Department of Psychiatry, Ghent University Hospital in Belgium. His research focuses on brain imaging and brain stimulation in psychiatric disorders.

Christine Purdon is a Full Professor in the Department of Psychology, University of Waterloo. Her researchfocuses on the development and persistence of anxiety and obsessive-compulsivedisorder.

Gilbert MD Lemmens is Associate Professor in Psychiatry, Department Head and Skin, Ghent University and Head of the Department of Psychiatry, Ghent University Hospital in Belgium. His research focuses onperinatal mental health, consultative and liaison psychiatry and family therapy for psychiatric disorders.

\section{Authors and Affiliations}

\section{Hannelore LN Tandt ${ }^{1}$ (D) - Inge Debruyckere ${ }^{1} \cdot$ Lemke Leyman $^{1} \cdot$ Roos Colman $^{2}$. Emiel A De Jaeghere ${ }^{3,4} \cdot$ Hanna Van Parys ${ }^{1} \cdot$ Chris Baeken $^{5,6} \cdot$ Christine Purdon $^{7}$. Gilbert MD Lemmens ${ }^{1,5}$}

1 Department of Psychiatry, Ghent University Hospital, Ghent, Belgium

2 Biostatistics Unit, Department of Public Health and Primary Care, Ghent University, Ghent, Belgium

3 Department of Internal Medicine and Pediatrics, Medical Oncology, Ghent University Hospital, Ghent, Belgium

4 Department of Human Structure and repair, Laboratory of Experimental Cancer Research, Ghent University, Ghent, Belgium

5 Department of Head and Skin, Psychiatry and Medical Psychology, Ghent University, Ghent, Belgium

6 Department of Psychiatry, Free University of Brussels, Brussels, Belgium

7 University of Waterloo, Waterloo, Canada 